\title{
Molecular, anatomical and physiological properties of a genetically modified soybean line transformed with $r d 29 A: A t D R E B 1 A$ for the improvement of drought tolerance
}

\author{
A.M. Polizel', M.E. Medri' ${ }^{1}$, K. Nakashima ${ }^{2}$, N. Yamanaka ${ }^{2}$, J.R.B. Farias ${ }^{3}$, \\ M.C.N. de Oliveira ${ }^{3}$, S.R.R. Marin $^{3}$, R.V.Abdelnoor ${ }^{3}$, F.C. Marcelino-Guimarães ${ }^{3}$, \\ R. Fuganti ${ }^{3}$, F.A. Rodrigues $^{3}$, R. Stolf-Moreira ${ }^{3}$, M.A. Beneventi ${ }^{4}$, A.A.P. Rolla ${ }^{1}$, \\ N. Neumaier ${ }^{3}$,K. Yamaguchi-Shinozaki ${ }^{2}$, J.F.C. Carvalho ${ }^{3}$ and A.L. Nepomuceno ${ }^{3}$ \\ ${ }^{1}$ Departamento de Genética, Universidade Estadual de Londrina, Londrina, PR, Brasil \\ ${ }^{2}$ Japan International Research Center for Agricultural Sciences, Tokyo, Japan \\ ${ }^{3}$ Embrapa Soja, Londrina, PR, Brasil \\ ${ }^{4}$ Departamento de Biotecnologia, Universidade Federal do Rio Grande do Sul, \\ Porto Alegre, RS, Brasil
}

Corresponding author: A.L. Nepomuceno

E-mail: nepo@cnpso.embrapa.br

Genet. Mol. Res. 10 (4): 3641-3656 (2011)

Received April 29, 2011

Accepted September 22, 2011

Published October 21, 2011

DOI http://dx.doi.org/10.4238/2011.October.21.4

\begin{abstract}
We evaluated the molecular, anatomical and physiological properties of a soybean line transformed to improve drought tolerance with an $r d 29 A$ :AtDREB1A construct. This construct expressed dehydrationresponsive element binding protein DREB1A from the stress-inducible $r d 29 A$ promoter. The greenhouse growth test included four randomized blocks of soybean plants, with each treatment performed in triplicate. Seeds from the non-transformed soybean cultivar BR16 and from the genetically modified soybean P58 line ( $\mathrm{T}_{2}$ generation) were grown at $15 \%$ gravimetric humidity for 31 days. To induce water deficit, the humidity was reduced to $5 \%$ gravimetric humidity (moderate stress) for 29 days
\end{abstract}


and then to $2.5 \%$ gravimetric humidity (severe stress). AtDREB1A gene expression was higher in the genetically modified P58 plants during water deficit, demonstrating transgene stability in $\mathrm{T}_{2}$ generations and induction of the $r d 29 A$ promoter. Drought-response genes, including GmPI-PLC, GmSTP, GmGRP, and GmLEA14, were highly expressed in plants submitted to severe stress. Genetically modified plants had higher stomatal conductance and consequently higher photosynthetic and transpiration rates. In addition, they had more chlorophyll. Overexpression of $A t$ DREB1A may contribute to a decrease in leaf thickness; however, a thicker abaxial epidermis was observed. Overexpression of $A t$ DREB1A in soybean appears to enhance drought tolerance.

Key words: Anatomy; Gene expression; Glycine max; Physiology; Water deficit; DREB1A

\section{INTRODUCTION}

Plant growth is greatly affected by environmental abiotic stresses, such as drought, high salinity and low temperature. Among these stresses, drought is considered the most serious, causing substantial yield losses. In the USA, the primary world soybean producer, drought periods throughout the 2007 season caused a loss of US\$787.2 million in agricultural production. It is estimated that the drought caused a total economic impact of US\$ 1.3 billion in losses. Soybean losses reached more than US\$ 6.3 million (Flanders et al., 2007). In Brazil, the second highest world soybean producer, during the 2003/2004 and 2004/2005 crop seasons, the southern states, which are responsible for $40 \%$ of the country soybean production, lost more than $20 \%$ of their production due to water deficit, reaching US $\$ 2.3$ billion in economic losses (Embrapa, 2004; Conab, 2005).

Survival during drought requires mechanisms through which plants perceive soil water deficit and rapidly regulate their physiology to compensate (Turner, 1997). A good example of such a mechanism is the reduction of transpirational water loss by partial stomatal closure and decreased leaf expansion during early soil drying, which postpones loss of tissue water potential and irreversible damage (Jones, 1992).

These abiotic stresses trigger various biochemical and physiological responses in plants to acquire stress tolerance. The molecular response in plants to water deficit has been analyzed at the transcriptional level by studying gene expression changes during drought, high salinity and cold stress (Ingram and Bartels, 1996; Thomashow, 1999; Hasegawa et al. 2000; Bray, 1997, 2004; Kalefetoğlu and Ekmekçi, 2005). The products of the stress-inducible genes can be classified into two groups: 1) those that directly protect against environmental stresses and 2) those that regulate gene expression and signal transduction during the stress response (Bray, 1997; Shinozaki and Yamaguchi-Shinozaki, 1997; Thomashow, 1999; Hasegawa et al., 2000).

Drought induces the expression of abscisic acid (ABA)-dependent and ABA-independent genes (Bray, 1997; Thomashow, 1999; Shinozaki and Yamaguchi-Shinozaki, 1997, 2000), which indicates the existence of a complex regulatory mechanism involved in the perception of abiotic stress signals (Shinozaki and Yamaguchi-Shinozaki, 1997, 2000; Zhu, 2001).

Analysis of the promoter regions of genes in the ABA-independent pathway that are 
involved in protecting cellular structures during stress has shown an essential cis-element with the core sequence A/GCCGAC named the dehydration responsive element (DRE) (Kasuga et al. 2004). These proteins are classified into two groups, DREB1 (DREB1A, DREB1B and DREB1C) and DREB2 (DREB2A and DREB2B). Both groups possess a conserved DNAbinding domain also found in ethylene-responsive element binding factor (ERF) and AP2 proteins, which was first identified in APETALA2 (Okamuro et al., 1997; Shinozaki and Yamaguchi-Shinozaki, 2000).

DREB1A overexpression delays death following withdrawal of irrigation in transgenic wheat (Pellegrineschi et al., 2004), whereas improvements in tolerance to drought, salinity and low-temperature stresses have been reported in Arabidopsis (Kasuga et al., 1999), potato (Behnam et al., 2007, tobacco (Kasuga et al., 2004), rice (Oh et al., 2005) and wheat (Pellegrineschi et al., 2002).

In our study, drought-sensitive soybean cultivar BR16 was transformed with the rd29A:AtDREB1A genetic construct generating a novel soybean line, P58. We report an increase in DREB transcription factor expression when plants of the genetically modified (GM) line P58 were submitted to water deficit treatment. In addition, we evaluated the genetic stability of the GM line P58. Thus, the objectives of this study were: 1) to determine whether the $r d 29 A$ :AtDREB1A genetic construct activates stress-inducible $A t \mathrm{DREB} 1 \mathrm{~A}$ protein target genes in soybean, 2) to determine the effects of $r d 29 A$ :AtDREB1A on drought tolerance by measuring plant responses, such as photosynthesis, stomatal conductance, chlorophyll content and transpiration rate, and 3 ) to evaluate whether the DREB1A gene promotes anatomical alterations in GM soybean plants.

\section{MATERIAL AND METHODS}

\section{Plant material, growth conditions and statistical design}

Adrought-sensitive Brazilian soybean cultivar BR16(Oya et al., 2004) was transformed with $r d 29$ A:AtDREB1A (Patent Nos. P3183458 and P3178672) construct. A rd29A:AtDREB1A construct positive soybean line, P58, was obtained by particle-bombardment transformation according to Aragão et al. (2000) and Rech et al. (2008), and it was submitted to drought in a greenhouse experiment.

GM soybean plants from the P58 line at the $\mathrm{T}_{2}$ generation and control plants (BR16 non-GM) were cultivated in pots containing sand and soil under $15 \%$ gravimetric humidity (GH) for 31 days post-sowing until reproductive stage $\mathrm{R}_{1}$ (Fehr and Caviness, 1977) in a greenhouse. Immediately after $\mathrm{R}_{1}$, irrigation was withheld from the drought-stress treatment pots until the GH values decreased to 5\% (moderate stress). Twenty-nine days later, irrigation was further reduced to $2.5 \% \mathrm{GH}$ (severe stress) for approximately 30 days until harvesting. Control plants were kept at $15 \%$ of GH throughout the experiment. To keep the pots at the desired GH, they were weighed twice a day and water was added as needed (Casagrande et al., 2001). The experiment was performed in a randomized complete block design with a 2 × 2 factorial arrangement of the treatments involving two GHs (drought stress and normal condition) and two genotypes (GM P58 and BR16) with four blocks and three biological repetitions per treatment inside each block. The temperature and air humidity in the greenhouse were monitored and maintained between $17^{\circ}$ and $40^{\circ} \mathrm{C}$ and between 25 and $90 \%$, respectively. All pots were irrigated twice a week with $50 \mathrm{~mL}$ balanced nutrient solution ( $\mathrm{pH}$ 6.6) (Hewitt, 1966). 


\section{RNA extraction and RT-qPCR analysis}

The third leaflet from each plant from all three repetitions per treatment was collected separately, immediately frozen in liquid nitrogen, and stored at $-86^{\circ} \mathrm{C}$ until RNA extraction. Samples were collected at 20 (moderate stress), 34 and 41 days (severe stress) of water deficit treatment. Total RNA was extracted using Trizol reagent (Invitrogen) according to manufacturer instructions. Two RNA pools were established: pool 1 had RNA extracted from plants from blocks 1 and 2, and pool 2 had RNA from plants from blocks 3 and 4. Total RNA was transcribed into cDNA using Reverse Transcriptase MML and oligo-dT primers (Invitrogen, Carlstad, USA), as described by Panchuk et al. (2002).

Candidate genes that respond to drought in Arabidopsis thaliana GM plants overexpressing DREB1A were determined from the literature. The DREB1A stress-inducible target genes GmLEA14 (late e embryogenesis abundant), encoding a contributor to osmotic stress protection in both embryonic and vegetative tissues (Accession No. CA784216); GmGR-RBP, encoding a glycine-rich RNA-binding protein (Accession No. AF169205); GmPI-PLC, encoding a phospholipase $\underline{\underline{C}}$ (Accession No. U41474); and GmSTP, encoding a sorbitol transporter protein (Accession No. AJ563367), were selected for analysis.

All primers were designed using the Primer Express v. 3.0 software (Applied Biosystems). Sequences were selected near the 3 ' region taking into account the product length (amplicons from 75 to $180 \mathrm{bp}$ ), optimal PCR annealing temperature and the likelihood of primers to self-anneal., GmRNA18S (Accession No. X02623.1) was used as a reference gene for normalization. The PCR reactions were performed in triplicate using $500 \mathrm{nM}$ of each forward and reverse primer, 12.5 $\mu$ L Platinum SYBR Green qPCR SuperMix UDG Kit (Invitrogen) and $5 \mu \mathrm{L}$ of a 1:10 (v/v) dilution of cDNA in a total volume of $25 \mu \mathrm{L}$. The PCR parameters were: $50^{\circ} \mathrm{C}$ for $2 \mathrm{~min}, 95^{\circ} \mathrm{C}$ for $2 \mathrm{~min}$, and 40 cycles of $95^{\circ} \mathrm{C}$ for $15 \mathrm{~s}, 62^{\circ} \mathrm{C}$ for $30 \mathrm{~s}$ and $72^{\circ} \mathrm{C}$ for $1 \mathrm{~min}$. An amplification efficiency curve was determined for each gene using four cDNA dilutions $\left(10,10^{-1}, 10^{-2}\right.$ and $\left.10^{-3}\right)$. To identify non-specific PCR products and primer dimers, a melting curve analysis was performed immediately after amplification. Relative gene expression was determined by the $2^{-\Delta \Delta C \mathrm{CT}}$ method (Livak and Schmittgen, 2001). Statistical analysis of the data were performed using the REST 2008 v. 2.0.7 software (Pfaffl et al., 2002), which enables the calculation of $P$ values for each sample group and $95 \%$ confidence intervals. P represents the probability that differences between sample and control group means are due to chance and is calculated by performing 2000 random relocations of the data.

\section{Physiological analysis and plant height}

Photosynthesis, stomatal conductance, transpiration rate and chlorophyll content were measured for each treatment (BR16 stressed, BR16 non-stressed, P58 stressed and P58 nonstressed) after 6, 12, 20, 27 (moderate stress), 34, 38, 41, 43, 48, 50, 54, and 57 days (severe stress) of water deficit treatment using a portable photosynthesis system (LI-6400) and a chlorophyll meter (SPAD-502).

Plant height was measured in each treatment after 12, 20 and 27 days of water treatment.

ANOVA (analysis of variance) and Tukey post-hoc test were performed using the SAS software. 


\section{Photonic and scanning electron microscopy analysis}

Anatomical analysis was performed on 1- $\mathrm{cm}^{2}$ leaflet cuts using a photonic microscope and a scanning electron microscope. Samples (BR16 and GM P58) from stressed and nonstressed plants were collected at two distinct time-points: 1) the $\mathrm{R}_{2}$ plant development stage (Fehr and Caviness, 1977), 20 days post-treatment during moderate stress $(5 \% \mathrm{GH})$, and 2 ) the $\mathrm{R}_{4}$ stage, 34 days post treatment during severe stress $(2.5 \% \mathrm{GH})$.

For photonic microscopy analysis, leaf material was submerged in 50\% FAA fixative reagent $(0.5 \mathrm{~mL}$ formol, acetic acid and $9 \mathrm{~mL}$ alcohol 50\%). The samples were dehydrated in an alcohol series and diafanized in xylene. Infiltration and blocking were performed in paraffin, and leaf material was sliced into $10-\mu \mathrm{m}$-thick sections using a rotary microtome. Sections were fixed on glass microscope slides for $2-6 \mathrm{~h}$ at $40^{\circ} \mathrm{C}$. Deparaffination and rehydration were performed by soaking the slides in xylene for $40 \mathrm{~min}$ and ethanol-xylene (1:1) for $1 \mathrm{~min}$, followed by five washes with a descending ethanol gradient for 2 min each. Sections were stained with astra blue for $5 \mathrm{~min}$, and excess stain was removed by washing the slides with running water for a few seconds. The slides were then stained with basic fuchsine for $15 \mathrm{~min}$ and washed again. This was followed by tissue dehydration in a series of five washes in an ascending ethanol gradient for 2 min each. Finally, the slides were washed with ethanol-xylene (1:1) for $2 \mathrm{~min}$ and xylene for $5 \mathrm{~min}$. Sections mounted in Canada balsam were covered with glass cover slips before microscopic analysis (Johansen, 1940). Histometric analysis was performed using the Motic Images 20001.3 software. ANOVA and Tukey test were performed using SAS.

For scanning electron microscopy, the samples were fixed in glutaraldehyde/paraformaldehyde (Karnovsky modified: glutaraldehyde $2.5 \%$ and paraformaldehyde $2.5 \%$ in 0.1 $\mathrm{M}$ phosphate buffer), washed in $0.1 \mathrm{M}$ phosphate buffer, fixed in $1 \% \mathrm{OsO}_{4}$, washed again in phosphate buffer, dehydrated in a descending ethanol gradient (50-100\% ethanol) and dried with $\mathrm{CO}_{2}$ using Bal-Tec/CPD-030 (Critical Point Dryer) equipment. The dried samples were mounted onto aluminum stubs, fixed with carbon tape, and coated with gold powder using Bal-Tec/SCD-050 (Sputter Coater) equipment. Anatomical evaluations and registers were performed using a scanning electron microscope (Philips FEI Quanta 200).

\section{RESULTS}

\section{Water deficit stress-dependent changes in gene expression}

RT-qPCR analysis was performed to monitor the relative expression of the AtDREB1A transgene in the $\mathrm{T}_{2}$ generation of the P58 transgenic line under stressed and non-stressed conditions. The P58 non-stressed plants served as control, and 18S rRNA was used as a constitutive reference. This analysis revealed that the AtDREB1A transgene was inserted in the genome of $\mathrm{T}_{2}$ generation plants and that its expression increased under water deficit conditions (Figure 1).

At1g01470 (LEA14), At5g58670 (PI-PLC), At4g35300 (carbohydrate transporter) and At2g21660 (GR-RBP) are downstream genes of DREB1A in Arabidopsis thaliana (Maruyama et al., 2004). Therefore, expression analysis was performed to verify if their orthologous, the putative genes GmLEA14, GmPI-PLC, GmGR-RBP and GmSTP, respectively, are also regulated by DREB1A in soybean. 


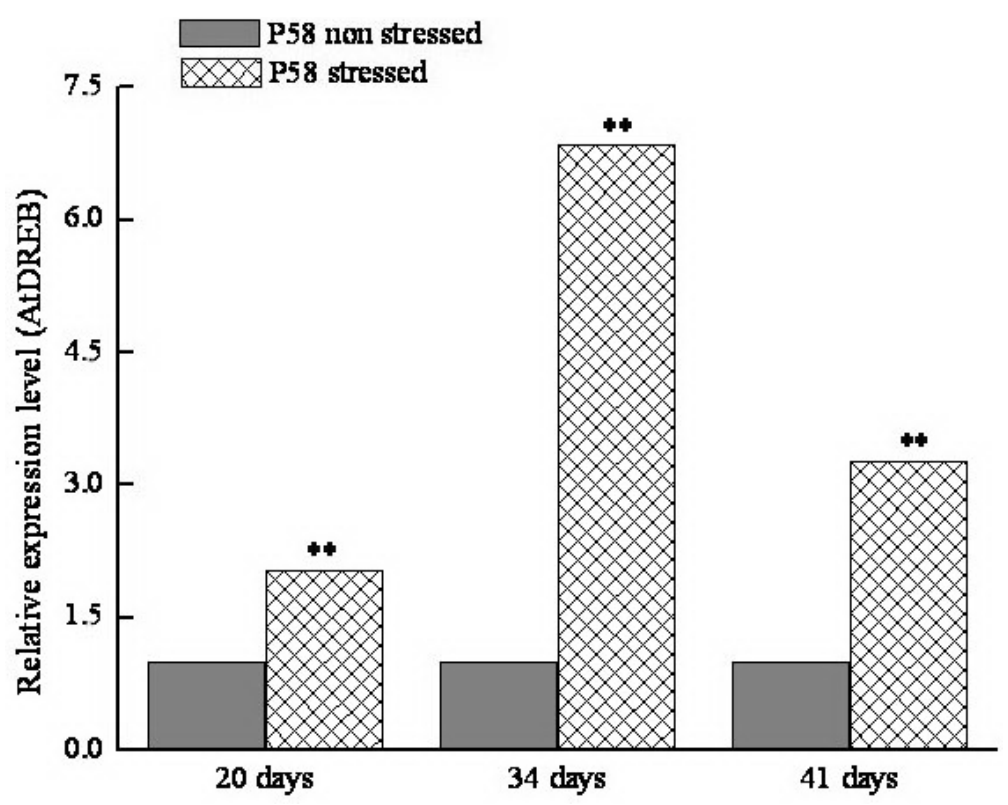

Figure 1. Gene expression analysis by RT-qPCR. Brazilian genetically modified P58 soybean lines were submitted to water deficit treatment, and the AtDREB1A transgene was analyzed after 20,34 and 41 days of treatment. Significant differences between P58 non-stressed plants were analyzed by the REST 2008 software $(* \mathrm{P} \leq 0.05$, $* * \mathrm{P} \leq 0.01)$.

GmLEA14 and GmPI-PLC showed decreased expression after 34 days of severe stress in BR16 and P58 stressed plants and P58 non-stressed plants. However, after 41 days of severe stress, GmLEA14 expression was higher in the GM P58 plant, both in stressed and non-stressed lines, when compared to control plants. In addition, GmPI-PLC gene expression increased in BR16 stressed plants and the GM P58 non-stressed and stressed plants (Figures 2A,B).

GmSTP gene expression level was not increased in non-transgenic BR16 plants under water deficit conditions, but GmSTP showed reduced expression after 34 days of severe stress in comparison to the control plants. GmSTP expression in GM P58 plants was down-regulated after 20 days of moderate stress and up-regulated after 41 days of severe stress (Figure 2C).

After 20 days of moderate stress, GmGR-RBP gene expression increased in stressed BR16 and P58 plants. After 41 days of severe stress, an increase in gene expression was also detected in stressed BR16 and non-stressed P58 plants. However, after 34 days of severe stress, BR16 and P58 plants had decreased GmGR-RBP gene expression levels (Figure 2D).

\section{Physiological analysis}

Stomatal conductance, photosynthesis and transpiration rate were measured in stressed and non-stressed BR16 and P58 plants after 6, 12, 20, 27 (moderate stress), 34, 38, 41, 43, 48, 50, 54 and 57 days (severe stress) of water deficit stress. Each variable was higher in GM P58 plants that were stressed and non-stressed when compared to BR16 plants after 50, 54 and 57 days of water deficit (Figures 3A,B,C). The photosynthetic rate was higher in stressed 
GM P58 plants (2.5\% GH) when compared to BR16 plants under normal conditions (15\% de $\mathrm{GH})$ after 57 days.
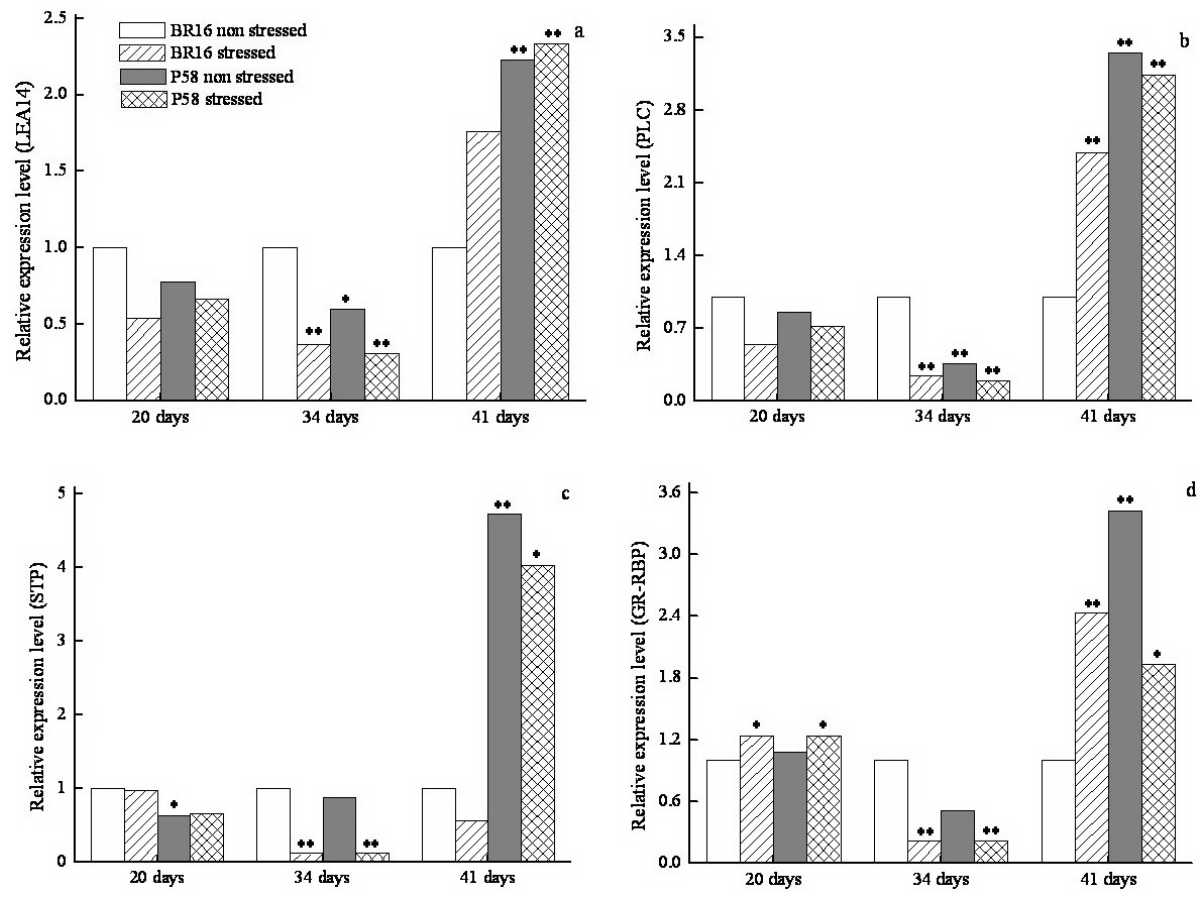

Figure 2. Gene expression analysis by RT-qPCR. Two Brazilian soybean genotypes, a genetically modified P58 line and non-transformed BR16 plants, were submitted to water deficit treatment, and the genes A. GmLEA14, B. $G m P L C$, C. GmSTP, and D. GmGR-RBP were analyzed after 20, 34 and 41 days of water deficit treatment. Significant differences between BR16 non-stressed plants were analyzed by the REST 2008 software $(* \mathrm{P} \leq 0.05, * * \mathrm{P} \leq 0.01)$.

Chlorophyll content was higher in BR16 plants at 15 and 5\% GH, when compared to P58 plants during moderate stress (12-27 days). However, BR16 stressed plants began reducing chlorophyll content after 38 days of water stress, reaching nearly $0 \mathrm{mg} / \mathrm{cm}^{2}$ after 57 days. After 54 days of water deficit, P58 plants (15 and 2.5\% GH) had higher chlorophyll content than BR16 plants (15 and 2.5\% GH) (Figure 3D).

\section{Anatomical analysis and morphological observations}

Morphological differences were not detected between GM P58 and BR16 plants by visual analysis of leaflet epidermal structures, including the stomata and trichomes (glandular and non-glandular), using scanning electron microscopy (Figures 4a to 4f). The mesophyll was dorsoventral, showing a biserial layer of palisade parenchyma with elongated cells of different sizes and spongy parenchyma with two or three layers of irregular cells (Figure 5).

Optical microscopic observation of the leaflets detected differences between droughtstressed and non-stressed plants. A reduction in leaflet thickness was detected only after 34 

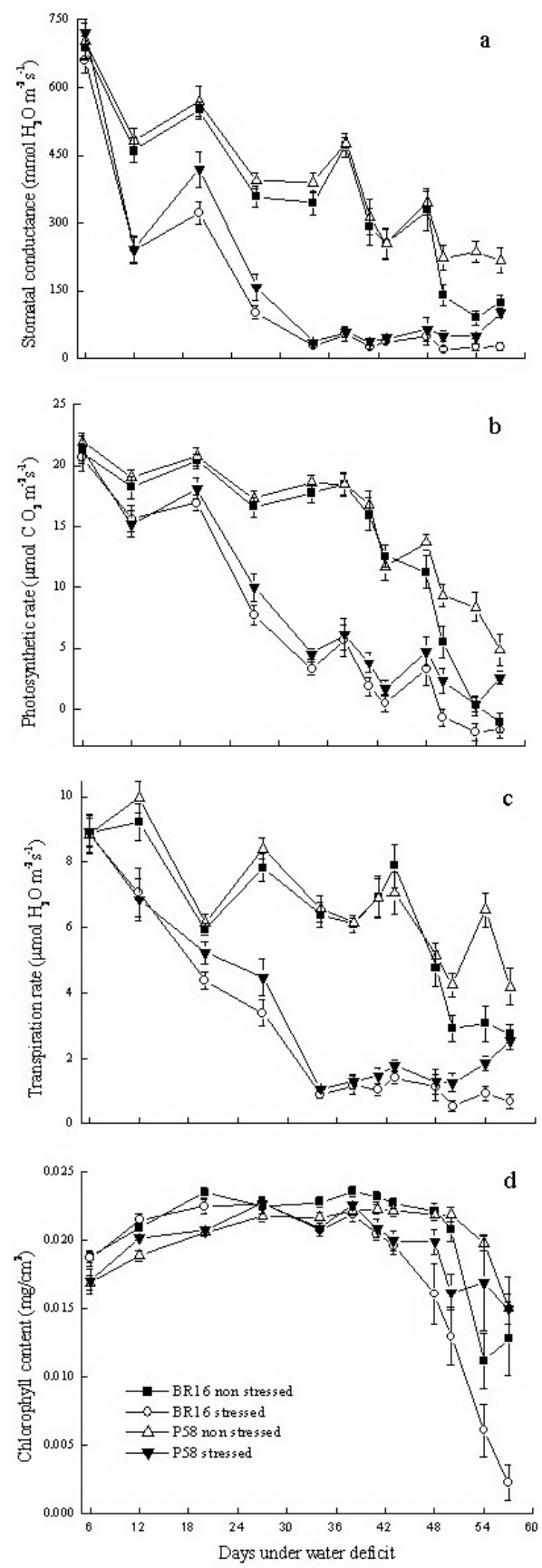

Figure 3. Physiological responses of the conventional soybean cultivar BR16 and GM P58 plants to drought. Plants treated and untreated were collected after 6, 12, 20, 27, 34, 38, 41, 43, 48, 50, 54 and 57 days of water deficit treatment. Vertical bars between each line correspond to the standard error and differences determined by the Tukey test. Dots where bars do not overlap indicate differences by the Tukey test $(\mathrm{P} \leq 0.05)$. 
days of stress at $2.5 \% \mathrm{GH}$ (Table 2). The palisade parenchyma layer in GM P58 plants was thicker than in BR16 plants after 20 and 34 days of the treatment (Tables 1 and 2); however, differences between stressed and non-stressed treatments were observed only after 34 days. The width of palisade cells was reduced in stressed plants under $2.5 \% \mathrm{GH}$ treatment (Table 2). The thickness of spongy parenchyma was reduced only in GM P58 drought-stressed plants when compared to non-stressed GM plants after 34 days (Table 2). In each treatment, the abaxial epidermis was thicker in GM P58 plants than in BR16 plants (Tables 1 and 2). The lengths of palisade cells and adaxial epidermis of the P58 and BR16 plants were not different between the $5 \% \mathrm{GH}$ and $2.5 \% \mathrm{GH}$ (data not shown).
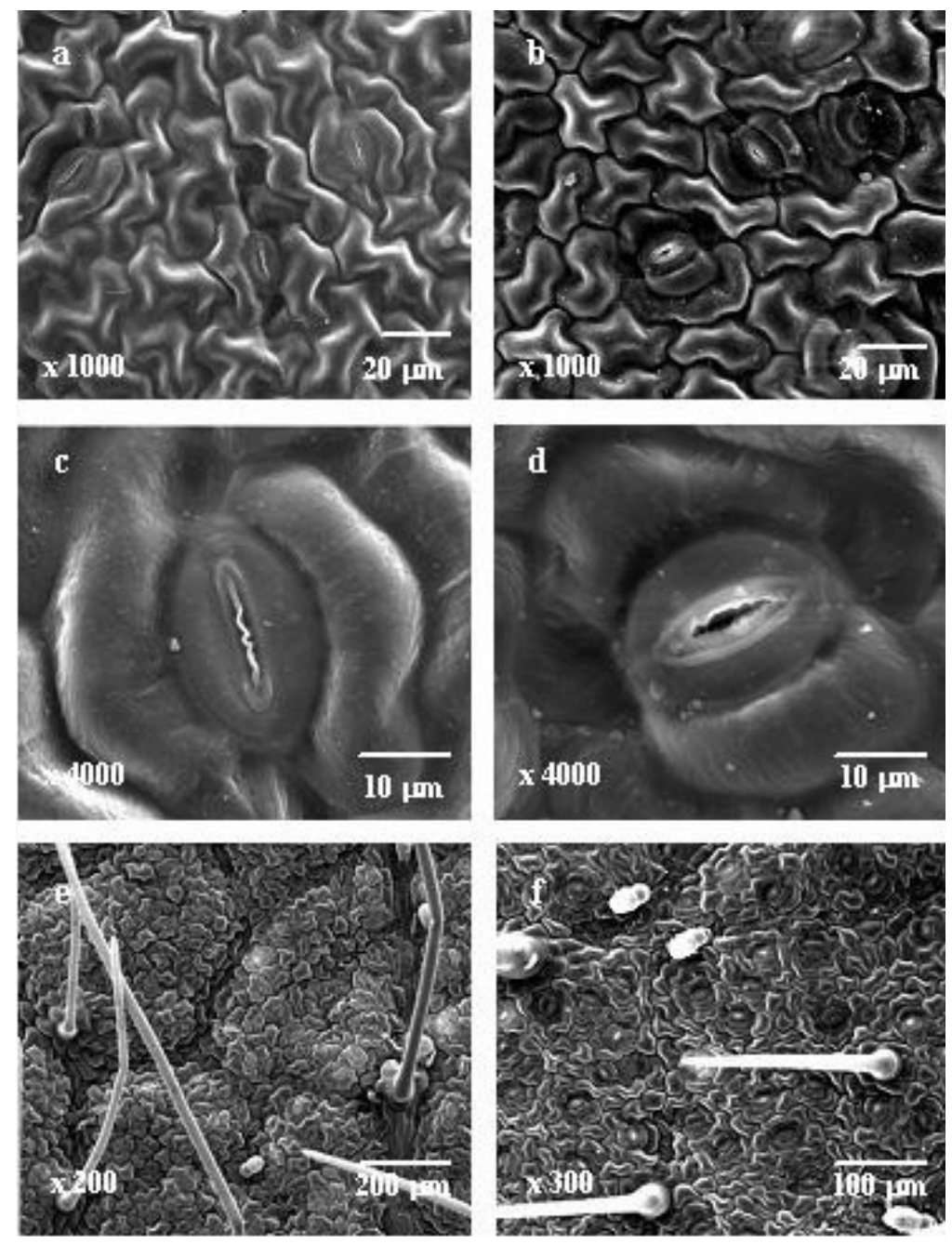

Figure 4. Scanning electron microscopy of tissue sections from drought-stressed soybean cultivars. The central leaflet of the third upper leaf is shown in detail. The epidermis, stomata, glandular and non-glandular trichomes from a. control BR16 plants at 15\% GH, b. GM P58 line at 5\% GH, c. BR16 (15\% GH), d. GM P58 at 5\% GH, e. BR 16 at $5 \% \mathrm{GH}$, and f. GM P58 at 5\% GH. 

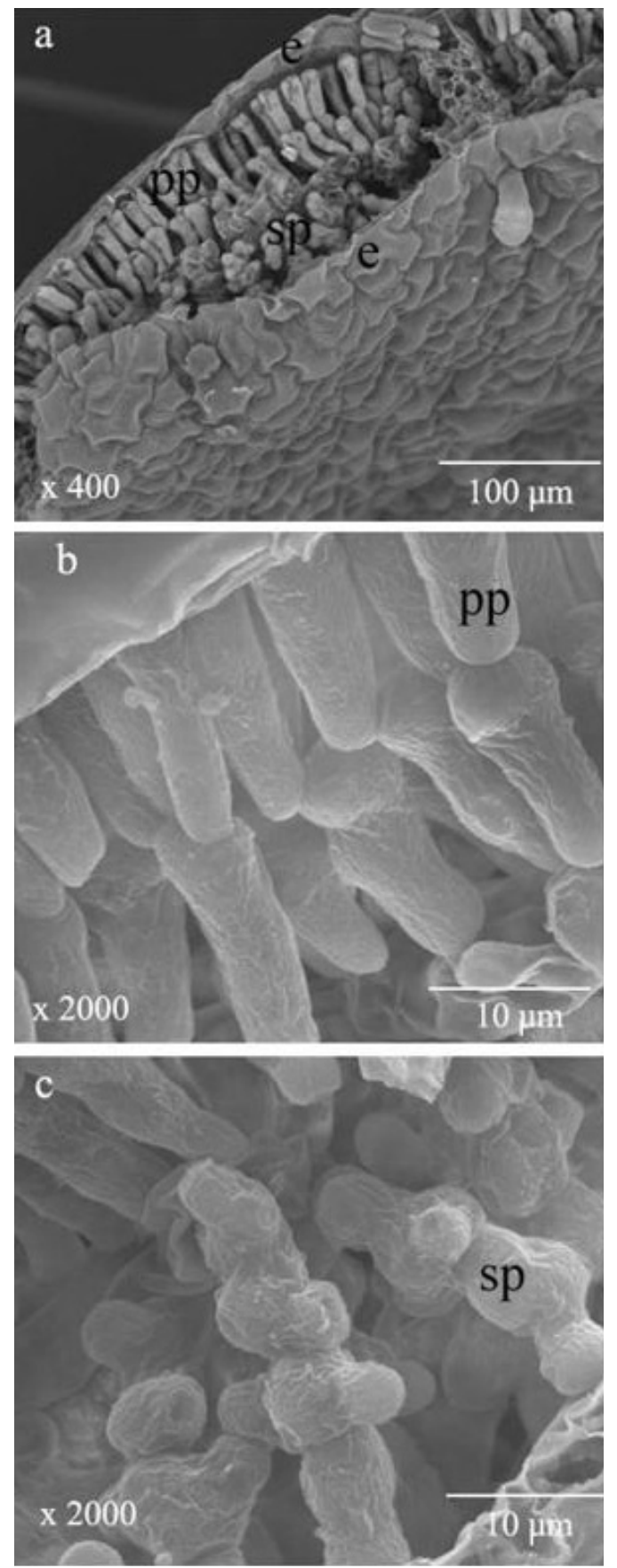

Figure 5. Scanning electron microscopy of tissue sections from soybean leaflet mesophyll. The central leaflet of the third upper leaf is shown in detail. The epidermis, palisade parenchyma and spongy parenchyma from a. BR 16 at $2.5 \%$ GH, b. GM P58 at 15\% GH, c. BR16 at 15\% GH. e. epidermis, pp = palisade parenchyma, sp = spongy parenchyma. 


\begin{tabular}{|c|c|c|c|}
\hline & Treatment $(5 \% \mathrm{GH})$ & Control $(15 \% \mathrm{GH})$ & Average \\
\hline \multicolumn{4}{|c|}{ Leaf thickness $(\mu \mathrm{m})$} \\
\hline BR16 & 485.8467 & 517.6833 & $501.76 \mathrm{~ns}$ \\
\hline P58 & 487.6133 & 510.6433 & 500.13 \\
\hline Average & $515.16 \mathrm{~ns}$ & 486.73 & \\
\hline \multicolumn{4}{|c|}{ Palisade parenchyma $(\mu \mathrm{m})$} \\
\hline BR16 & 223.6933 & 229.46 & $225.834 * \mathrm{a}$ \\
\hline P58 & 206.9 & 216.36 & $210.866 \mathrm{~b}$ \\
\hline Average & $214.456 * \mathrm{~A}$ & $222.081 \mathrm{~A}$ & \\
\hline \multicolumn{4}{|c|}{ Palisade cell width $(\mu \mathrm{m})$} \\
\hline BR16 & 30.55 & 29.8741 & $30.2120 \mathrm{~ns}$ \\
\hline P58 & 28.5608 & 31.0516 & 29.8062 \\
\hline Average & $30.4629 \mathrm{~ns}$ & 29.5554 & \\
\hline \multicolumn{4}{|c|}{ Spongy parenchyma (um) } \\
\hline BR16 & 191.7967 & 204.1967 & $197.993 \mathrm{~ns}$ \\
\hline P58 & 195.9933 & 208.6933 & 202.343 \\
\hline Average & $193.893 \mathrm{~ns}$ & 206.443 & \\
\hline \multicolumn{4}{|c|}{ Abaxial epidermis $(\mu \mathrm{m})$} \\
\hline BR16 & 39.0367 & 40.5767 & $39.620 * \mathrm{a}$ \\
\hline P58 & 42.6267 & 43.4733 & $43.048 \mathrm{~b}$ \\
\hline Average & $40.828 * \mathrm{~A}$ & $41.936 \mathrm{~A}$ & \\
\hline
\end{tabular}

Samples from drought-stressed and non-stressed plants after 20 days of treatment ( $5 \% \mathrm{GH})$ were evaluated for leaf thickness, palisade parenchyma, width of the palisade cell, spongy parenchyma, and abaxial epidermis. Means followed by the same capital letters (line) or non-capital letters (column) did not differ by the Tukey test $(\mathrm{P} \leq 0.05)$.

\section{Table 2. Morphometric evaluation of the BR16 and GM P58 plants.}

\begin{tabular}{|c|c|c|c|}
\hline & Treatment $(2.5 \% \mathrm{GH})$ & Control $(15 \% \mathrm{GH})$ & Average \\
\hline \multicolumn{4}{|c|}{ Leaf thickness $(\mu \mathrm{m})$} \\
\hline BR16 & 468.77 & 830.5633 & $501.04 * \mathrm{a}$ \\
\hline P58 & 445.04 & 531.7933 & $485.31 \mathrm{a}$ \\
\hline Average & $456.42 * \mathrm{~B}$ & $529.93 \mathrm{~A}$ & \\
\hline \multicolumn{4}{|c|}{ Palisade parenchyma $(\mu \mathrm{m})$} \\
\hline BR16 & 221.5266 & 243.8733 & $232.698 * a$ \\
\hline P58 & 197.0233 & 222.83 & 209.924 b \\
\hline Average & $209.271 * \mathrm{~B}$ & $233.351 \mathrm{~A}$ & \\
\hline \multicolumn{4}{|c|}{ Palisade cell width $(\mu \mathrm{m})$} \\
\hline BR16 & 32.5766 & 34.4533 & $33.5137^{*} \mathrm{a}$ \\
\hline P58 & 33.17 & 35.4233 & $34.2967 \mathrm{a}$ \\
\hline Average & $32.8729 \mathrm{~B}$ & $34.9375 \mathrm{~A}$ & \\
\hline \multicolumn{4}{|c|}{ Spongy parenchyma $(\mu \mathrm{m})$} \\
\hline BR16 & $184.6290 \mathrm{aA}$ & $211.5483 \mathrm{aA}$ & 198.674 \\
\hline P58 & $173.2616 \mathrm{bA}$ & $224.9454 \mathrm{aA}$ & 197.98 \\
\hline Average & 178.698 & 217.956 & \\
\hline \multicolumn{4}{|c|}{ Abaxial epidermis $(\mu \mathrm{m})$} \\
\hline BR16 & 31.9033 & 34.9433 & $33.223 * \mathrm{~b}$ \\
\hline P58 & 36.57 & 36.78 & $36.678 \mathrm{a}$ \\
\hline Average & $34.237 * \mathrm{~A}$ & $35.766 \mathrm{~A}$ & \\
\hline
\end{tabular}

Samples drought-stressed and non-stressed after 34 days of the treatment $(2.5 \% \mathrm{GH})$ were evaluated for leaf thickness, palisade parenchyma, width of the palisade cell, spongy parenchyma, and abaxial epidermis. Means followed by the same capital letters (line) or non-capital letters (column) did not differ by the Tukey test $(\mathrm{P} \leq 0.05)$.

Morphological observations showed that $r d 29 A$ :AtDREB1A plants exhibited stunted growth under stressed and non-stressed conditions in the greenhouse (Figure 6). 


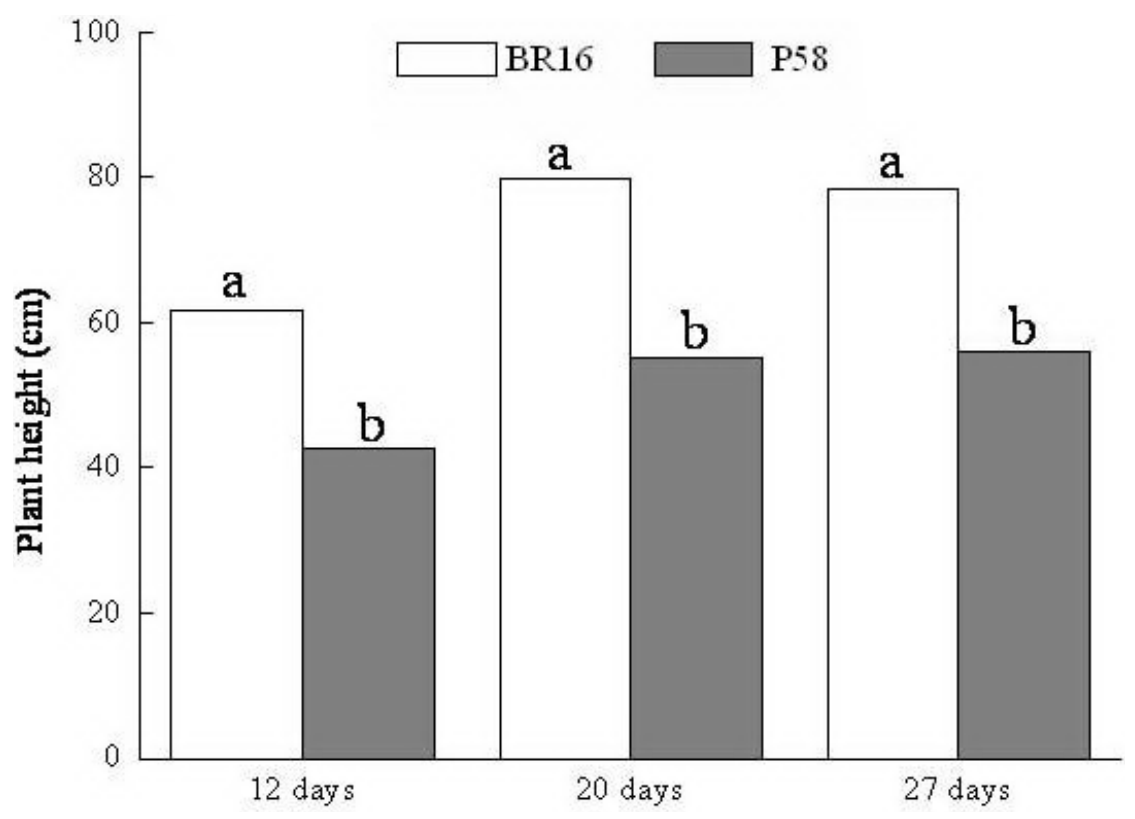

Figure 6. Plant height of stressed and non-stressed conventional soybean cultivar BR16 and GM P58 plants measured after 12, 20 and 27 days under treatment ( $5 \% \mathrm{GH})$. Means followed by the same letters did not differ by the Tukey test $(\mathrm{P} \leq 0.05)$.

\section{DISCUSSION}

Drought-dependent AtDREB1A expression in GM P58 plants indicated transgene stability in the $\mathrm{T}_{2}$ generation. Insertion of the transgene in the soybean genome was confirmed, as well as induction of the $A$. thaliana $r d 29 A$ promoter.

The LEA14 gene of $A$. thaliana responds to drought and cold stress treatment (Sakuma et al., 2006). This gene has a DRE core motif in the promoter region (Maruyama et al., 2004) that is regulated by both DREB1A and DREB2A (Qin et al., 2008). However, studies have not been performed using the GmLEA14 promoter region. Our study suggests that this gene is activated during drought conditions by DREB1A because P58 transgenic plants had higher LEA14 gene expression after 41 days of severe water deficit stress.

The PLC1 gene is regulated by DREB1A in A. thaliana (Maruyama et al., 2004). We reported that drought-stressed and non-stressed GM P58 plants had higher GmPI-PLC expression after 41 days of severe stress; however, BR16 plants under water deficit stress also had increased GmPI-PLC expression. These data suggest that GmPI-PLC is activated by other mechanisms, such as by ABA. In A. thaliana, members of the PLC gene family are activated by ABA (Tasma et al., 2008). Enhanced expression of ZmPLC1 also improves drought tolerance in maize: under drought stress conditions, transgenic plants have higher relative water content, better osmotic adjustment, increased photosynthetic rates, a lower percentage of ion leakage, less lipid membrane peroxidation and higher grain yield when compared to wild-type maize (Wang et al., 2008). 
GmSTP was over-expressed after 41 days of severe water stress in GM P58 stressed and non-stressed plants. Maruyama et al. (2004) identified the DRE core motif in the promoter region of the At4g35300 gene (sugar transport protein) that is regulated by DREB1A, suggesting that the GmSTP gene may also be regulated by DREB1A under drought conditions. However, studies of this promoter region have not been performed. Sorbitol transport, an important cell osmotic potential regulator, is performed by the protein product of GmSTP. Sorbitol accumulation in mature leaves and roots during water deficit can constitute $80 \%$ of the total solutes involved in osmotic adjustment (Bianco et al., 2000).

GR-RBPs post-transcriptionally regulate gene expression in plants under various stress conditions. These proteins are expressed abundantly in the guard cells and have been implicated in the control of stomata opening and closing (Kim et al., 2008). AtGR-RBP expression is induced by DREB1A (Maruyama et al., 2004). In our research, GM P58 and nonGM BR16 stressed plants showed a reduction in $G m G R-R B P$ gene expression after 34 days of severe stress. In other studies, the $G R-R B P$ gene has been highly expressed during cold treatment but reduced during drought (Kim et al., 2005; Kwak et al., 2005). Our study confirmed the increase in $G m G R-R B P$ gene expression after 20 and 41 days of drought. Increased $G R$ $R B P$ gene expression has also been detected in A. thaliana in response to drought, cold and ABA treatment (Sachetto-Martins et al., 1995).

In A. thaliana, DREB1A expression increases within $1 \mathrm{~h}$ of stress; however, expression of DREB1A downstream genes is induced within $24 \mathrm{~h}$ (Maruyama et al., 2004). Our study corroborates these data, suggesting that after 34 days of water deficit stress, which coincided with the beginning of the severe stress treatment $(2.5 \% \mathrm{GH})$, DREB1A activated target gene expression. However, an increase in transcript level was only observed after 41 days of severe stress. During the initial moderate stress $(5 \% \mathrm{GH})$, over-expression of genes may also have occurred, but these data were not collected because the first evaluation was performed only after 20 days of water stress. Presumably, at this point, plants were already undergoing molecular responses to water deficit stress. Thus, differences in gene expression were observed for downstream genes, such as GmPI-PLC, GmLEA14 and GmSTP, in this treatment.

The non-stressed GM P58 plants also exhibited increased GmPI-PLC, GmGR-RBP, GmLEA14 and GmSTP gene expression after 41 days of water deficit severe stress. This response indicated that $15 \% \mathrm{GH}$ was not sufficient to supply plants with water because they were in the seed-filling stage. These responses may explain the physiological differences between GM P58 and BR16 plants, which were most evident after 50, 54 and 57 days of severe stress.

The higher stomatal conductance shown in stressed GM P58 plants compared to stressed BR16 plants allowed higher transpiration rates in the drought-stressed GM plants. High stomatal conductance under a low water potential may be explained by the maintenance of high cell turgor (Taiz and Zeiger, 2002). In our study, higher stomatal conductance may have been due to the expression of gene (s) related to osmotic adjustment, such as GmSTP, which was more intensely expressed during severe stress periods. Higher stomatal conductance in GM P58 plants promoted higher $\mathrm{CO}_{2}$ diffusion to the leaf mesophyll, improving photosynthetic rate. According to Cornic (2000), stomatal closure is considered one of the main causes of photosynthesis rate reductions because $\mathrm{CO}_{2}$ availability in the mesophyll is reduced. The higher photosynthetic rate presented here by transgenic plants agrees with data from Kasuga et al. (2004), in which tobacco plants containing a 35S:DREB1A construct showed higher photosynthetic activity compared to control plants. 
In our study, GM plants had higher chlorophyll content when compared to non-transformed plants. Similar results were reported in a study of transgenic rice that constitutively expressed $D R E$ $B 1 A$ : after water deficit stress, non-transformed plants began wilting and the leaves began to roll; reduction in chlorophyll content was more intense than in the transgenic plants (Oh et al., 2005).

Scanning electron microscopy analysis suggested that the AtDREB $1 A$ transgene insertion in soybean did not cause visual alterations in stomata structure, trichomes or leaflet epidermis surface. However, morphometric analysis identified a reduction in leaflet thickness, probably as a consequence of a thinner palisade parenchyma. GM P58 plants also showed a thinner palisade parenchyma when compared to BR16 control samples. This reduction may have been due to a higher proximity of the cellular layer, as the cell length was not reduced. Closer cells might represent an adaptation to low water availability in order to increase cell surface contact and facilitate the capture of light energy and gaseous elements, which are necessary for the photosynthetic process.

Reduced palisade cell width in drought-stressed plants indicates a decrease in turgescence. In addition, GM P58 plants presented a reduction in parenchyma spongy cell thickness when compared to the non-stressed transgenic lines, indicating that the insertion of the DREB gene did not induce differentiation into more xeromorphic characteristics. However, the average thickness of the abaxial epidermis was higher in transgenic plants when compared to non-transformed plants, suggesting that genes related to mesophyll protection were activated direct or indirectly by the transcription factor $A t \mathrm{DREB} 1 \mathrm{~A}$.

The use of the stress-inducible $r d 29 A$ promoter to drive AtDREB1A gene expression caused a reduction in the distance between internodes, which might be associated with overexpression under stress conditions. However, we observed this effect even in non-stressed plant. This suggests that plants at the control treatment $(15 \% \mathrm{GH})$ were suffering deficit in some way. DREB1A interacts with other transcription factors, such as the STZ zinc-finger transcription factor, which suppresses genes involved in photosynthesis and carbohydrate metabolism and has been suggested to be involved in the growth retardation of transgenic plants over-expressing DREB1A (Maruyama et al., 2004). However, use of the stress-inducible $r d 29 \mathrm{~A}$ promoter instead of the constitutive $35 \mathrm{~S} \mathrm{CaMV}$ promoter to over-express DREB1A should minimize the negative effects on plant growth (Kasuga et al., 1999). Copy number and positional effects of the insert might also cause leaking of the A.thaliana rd29 promoter in soybean P58 line.

In conclusion, insertion of the $r d 29 A$ :AtDREB1A genetic construct in soybean induced the expression of genes involved in drought response when plants were submitted to water deficit conditions. These alterations activated physiological drought response mechanisms and caused morphological alterations in leaflet thickness; however, a thicker abaxial epidermis may facilitate physiological adaptations in transgenic plants and function as a barrier to excessive luminosity, heat and evapotranspiration. Because improvement of stress tolerance is a major goal for soybean genetic engineering, successful production of DREB1A-transformed soybean plants is of great significance for breeding stress-tolerant cultivars. The present study demonstrates that the expression of AtDREB1A in soybean may offer an effective approach to enhance drought tolerance. Further studies are needed to assess its agricultural potential under field conditions.

\section{ACKNOWLEDGMENTS}

We thank Embrapa Soybean for use of the laboratory and greenhouse and JIRCAS 
(Japan International Research Center for Agriculture Science). N.K. was supported by a JSPS fellowship.

\section{REFERENCES}

Aragão FJL, Sarokin L, Vianna GR and Rech EL (2000). Selection of transgenic meristematic cells utilizing a herbicidal molecule results in the recovery of fertile transgenic soybean [Glycine max (L.) Merril] plants at a high frequency. Theor. Appl. Genet. 101: 1-6.

Behnam B, Kikuchi A, Celebi-Toprak F, Kasuga M, et al. (2007). Arabidopsis rd29A:DREB1A enhances freezing tolerance in transgenic potato. Plant Cell Rep. 26: 1275-1282.

Bianco RL, Rieger M and Sung SJS (2000). Effect of drought on sorbitol and sucrose metabolism in sinks and sources of peach. Physiol. Plant. 108: 71-78.

Bray EA (1997). Plant responses to water deficit. Trends Plant Sci. 2: 48-54.

Bray EA (2004). Genes commonly regulated by water-deficit stress in Arabidopsis thaliana. J. Exp. Bot. 55: 2331-2341.

Casagrande EC, Farias JRB, Neumaier N, Oya T, et al. (2001). Expressão gênica diferencial durante déficit hídrico em soja. Rev. Bras. Fisiol. Veg. 13: 168-184.

Conab - Companhia Nacional de Abastecimento (2005). Available at [http://www.conab.gov.br]. Accessed.........

Cornic G (2000). Drought stress inhibits photosynthesis by decreasing stomatal aperture - not by affecting ATP synthesis. Trends Plant Sci. 5: 187-188.

Embrapa - Empresa Brasileira de Pesquisa Agropecuária (2004). Available at [http://www.cnpso.embrapa.br]. Accessed.........

Fehr WR and Caviness CE (1977). Stages of Soybean Development. State University, Cooperative extension Service, Ames.

Flanders A, McKissick JC and Shepherd T (2007). Georgia economic losses due to 2007 drought. Center Rep. CR: 7-10.

Hasegawa PM, Bressan RA, Zhu JK and Bohnert HJ (2000). Plant cellular and molecular responses to high salinity. Annu. Rev. Plant Physiol. Plant Mol. Biol. 51: 463-499.

Hewitt EJ (1966). Sand and Water Culture Methods Used in the Study of Plant Nutrition. 2nd edn. Commonwealth Bureau of Horticulture and Plantation Crops, Maidstone.

Ingram J and Bartels D (1996). The molecular basis of dehydration tolerance in plants. Annu. Rev. Plant Physiol. Plant Mol. Biol. 47: 377-403.

Johansen DA (1940). Plant Microtechnique. McGraw-Hill Book Company, New York.

Jones HG (1992). Plants and Microclimate: A Quantitative Approach to Environmental Plant Physiology. 2nd edn. Cambridge University Press, Cambridge.

Kalefetoğlu T and Ekmekçi Y (2005). The effects of drought on plants and tolerance mechanisms. J. Sci. 18: 723-740.

Kasuga M, Liu Q, Miura S, Yamaguchi-Shinozaki K, et al. (1999). Improving plant drought, salt, and freezing tolerance by gene transfer of a single stress-inducible transcription factor. Nat. Biotechnol. 17: 287-291.

Kasuga M, Miura S, Shinozaki K and Yamaguchi-Shinozaki K (2004). A combination of the Arabidopsis DREB1A gene and stress-inducible $r d 29 \mathrm{~A}$ promoter improved drought- and low-temperature stress tolerance in tobacco by gene transfer. Plant Cell Physiol. 45: 346-350.

Kim JS, Jung HJ, Lee HJ, Kim KA, et al. (2008). Glycine-rich RNA-binding protein 7 affects abiotic stress responses by regulating stomata opening and closing in Arabidopsis thaliana. Plant J. 55: 455-466.

Kim YO, Kim JS and Kang H (2005). Cold-inducible zinc finger-containing glycine-rich RNA-binding protein contributes to the enhancement of freezing tolerance in Arabidopsis thaliana. Plant J. 42: 890-900.

Kwak KJ, Kim YO and Kang H (2005). Characterization of transgenic Arabidopsis plants overexpressing GR-RBP4 under high salinity, dehydration, or cold stress. J. Exp. Bot. 56: 3007-3016.

Livak KJ and Schmittgen TD (2001). Analysis of relative gene expression data using real time quantitative PCR and the 2_DDCT methods. Methods 25: 402-408.

Maruyama K, Sakuma Y, Kasuga M, Ito Y, et al. (2004). Identification of cold-inducible downstream genes of the Arabidopsis DREB1A/CBF3 transcriptional factor using two microarray systems. Plant J. 38: 982-993.

Oh SJ, Song SI, Kim YS, Jang HJ, et al. (2005). Arabidopsis CBF3/DREB1A and ABF3 in transgenic rice increased tolerance to abiotic stress without stunting growth. Plant Physiol. 138: 341-351.

Okamuro JK, Caster B, Villarroel R, Van MM, et al. (1997). The AP2 domain of APETALA2 defines a large new family of DNA binding proteins in Arabidopsis. Proc. Natl. Acad. Sci. U. S. A. 94: 7076-7081.

Oya T, Nepomuceno AL, Neumaier N, Farias JRB, et al. (2004). Drought tolerance characteristics of Brazilian soybean 
cultivars - evaluation and characterization of drought tolerance of various Brazilian soybean cultivars in the field. Plant Prod. Sci. 7: 129-137.

Panchuk II, Volkov RA and Schoffl F (2002). Heat stress- and heat shock transcription factor-dependent expression and activity of ascorbate peroxidase in Arabidopsis. Plant Physiol. 129: 838-853.

Pellegrineschi A, Ribaut JM, Trethowan R, Yamaguchi-Shinozaki K, et al. (2002). Progress in the genetic engineering of wheat for water-limited conditions. JIRCAS Work. Rep. 23: 55-60.

Pellegrineschi A, Reynolds M, Pacheco M, Brito RM, et al. (2004). Stress-induced expression in wheat of the Arabidopsis thaliana DREB1A gene delays water stress symptoms under greenhouse conditions. Genome 47: 493-500.

Pfaffl MW, Horgan GW and Dempfle L (2002). Relative expression software tool (REST) for group-wise comparison and statistical analysis of relative expression results in real-time PCR. Nucleic Acids Res. 30: e36.

Qin F, Sakuma Y, Tran LSP, Maruyama K, et al. (2008). Arabidopsis DREB2A-Interacting proteins function as RING E3 ligases and negatively regulate plant drought stress-responsive gene expression. Plant Cell 20: 1693-1707.

Rech EL, Vianna GR and Aragão FJL (2008). High-efficiency transformation by biolistics of soybean, common bean and cotton transgenic plants. Nat. Protoc. 3: 410-418.

Sachetto-Martins G, Fernandes LD, Félix DB and de Oliveira DE (1995). Preferential transcriptional activity of a glycinerich protein gene from Arabidopsis thaliana in protoderm -derived cells. Int. J. Plant Sci. 156: 460-470.

Sakuma Y, Maruyama K, Osakabe Y, Qin F, et al. (2006). Functional analysis of an Arabidopsis transcription factor, DREB2A, involved in drought-responsive gene expression. Plant Cell 18: 1292-1309.

Shinozaki K and Yamaguchi-Shinozaki K (1997). Gene expression and signal transduction in water-stress response. Plant Physiol. 115: 327-334.

Shinozaki K and Yamaguchi-Shinozaki K (2000). Molecular responses to dehydration and low temperature: differences and cross-talk between two stress signaling pathways. Curr. Opin. Plant Biol. 3: 217-223.

Taiz L and Zeiger E (2002). Plant Physiology, 3rd edn. Sinauer, Sunderland.

Tasma IM, Brendel V, Whitham SA and Bhattacharyya MK (2008). Expression and evolution of the phosphoinositidespecific phospholipase C gene family in Arabidopsis thaliana. Plant Physiol. Biochem. 46: 627-637.

Thomashow MF (1999). Plant cold acclimation: freezing tolerance genes and regulatory mechanisms. Annu. Rev. Plant Physiol. Plant Mol. Biol. 50: 571-599.

Turner NC (1997). Further progress in crop water relations. Adv. Agron. 58: 293-338.

Wang CR, Yang AF, Yue GD, Gao Q, et al. (2008). Enhanced expression of phospholipase C 1 (ZmPLC1) improves drought tolerance in transgenic maize. Planta 227: 1127-1140.

Zhu JK (2001). Cell signaling under salt, water and cold stresses. Curr. Opin. Plant Biol. 4: 401-406. 